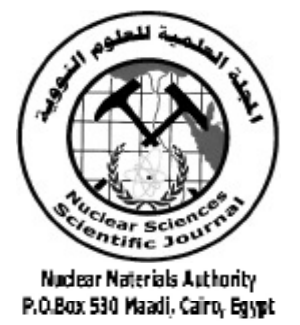

ISSN 2314-5609

Nuclear Sciences Scientific Journal

vol. 4 , p 133- 140

2015

\title{
FUNGAL ACTIVITY IN REDUCTION OF THE URANIUM CONTENT AND THE ACTIVITY CONCENTRATION OF OTHER RADIONUCLIDES IN SOME TENORM
}

\author{
TAREK F. MOHAMMADEN \\ Nuclear Materials Authority, P. O. Box 530, El-Maadi, Cairo, Egypt.
}

\begin{abstract}
The granitic tailing $(\mathrm{GW})$ and the phosphogypsum $(\mathrm{PG})$, solid wastes resulted from the leaching process of the U-bearing granite and manufacturing of the phosphoric acid from the phosphate rocks respectively, are considered as TENORM. Both of them retain considerable uranium concentration in addition to most of the original radium content as well as other radionuclides. Due to their enhanced radionuclide contents and their huge produced quantities, these wastes represent a real risk on man and the environment. The present work employed the fungal activity to reduce the uranium content and radium activity concentration in these radioactive solid wastes. Strain of the Aspergillus terreus (A.terreus) was isolated from the tested TENORM and was propagated on the appropriate Dox liquid media. Four controlling factors affecting the fungus leaching capability were investigated; the incubation period, solid/liquid ratio, incubation temperature and the initial $\mathrm{pH}$ where their optimum values were recorded as three days, $1 \%, 30{ }^{\circ} \mathrm{C}$ and 4 respectively. Testing of the optimum conditions together on the solid wastes revealed that the $A$. terreus reduced $66.9 \%$ and $62.5 \%$ of the uranium content in both the GW and PG wastes respectively. In parallel, the $A$. terreus removed $76.5 \%$ and $63 \%$ of the radium activity concentration in the GW and PG wastes.
\end{abstract}

\section{INTRODUCTION}

Naturally occurring radionuclides are present in many natural resources. Elevated concentrations of these radionuclides are often found in certain geological materials. The different human activities to exploit these resources lead to enhancing the radionuclides concentrations in the residues, by-products or the wastes resulted from the exploited resources. These resulted materials are referred as technologically enhanced naturally occurring radioactive materials (TENORM) and usually they impose exposure to radiation activity more than their natural resources (USEPA, 2002). The activities that lead to formation of the TENORM include, for instance, the mining and milling of ores which may be included within the front end of the nuclear fuel cycle or outside it. Due to their concentrated radioactivity and the large produced quantities, if these TENORM are not managed properly and safely, the environmental contamination over large areas and human healthy risks are possible for the following reasons (Rutherford, et al., 1994);

- They retain much of the radioactivity of the ore from which they were derived;

- Their radioactivity is very long lived;

- Their granular consistency to slime makes them susceptible to leaching, erosion or collapse under various conditions;

- The common method of surface disposal 
exposes a large surface area to the natural elements and thus increases the risk of release of radiation flux, radioactive and geochemically toxic dusts, and interaction with surface and subsurface water systems;

- The large surface area of these generally thin tailings deposits (or 'piles') adversely affects large areas of land and renders potentially valuable land unfit for other uses.

Therefore underground disposition, at restricted environmental and engineering conditions, is the favorable option worldwide to manage the TENORM although it is sometimes a costly option in addition to missing the opportunity to reuse these materials in several economic and civilian purposes if their radioactivity concentrations were reduced to safe limits.

However, several efforts were carried out to manage and exploit these materials. Among these efforts, the microorganisms (bacteria and/or fungi) played an important role to leach and recover the uranium and other metal from their bearing waste or from the original ores (Hefnawy et al., 2002 and 2003, Gabriel \& Tomas, 2003, Cabrera et al., 2005, Saravanan et al., 2007, Hung-Yee \& Yen-Peng, 2006, Fang \& Zhou, 2007 and Tong-Jiang \& YenPeng, 2009). The bioleaching process based on ability of the microorganisms to transform solid compounds into soluble and extractable elements which can be recovered (Sumera et al., 2002).

The fungi have been widely used in the bioleaching process due to their advantages over the bacterial leaching such as the ability to grow under higher $\mathrm{pH}$ and the faster leaching. Traditionally, the fungus excretes varieties of the organic acids (e.g. citric, oxalic, acetic and gluconic) which known as the lixiviates for bioleaching of heavy metals and uranium from the ore materials and the solid wastes (Hefnawy et al., 2003, Mulligan et al., 2005, Gu \& Wong, 2007 and Fozia et al., 2010).

Metal solubilization by fungi may have biotechnological potential for metal recovery from the industrial by-products and low-grade ores as well as other solid wastes (Mishra et al., 2009). Penicillium and Aspergillus are the most important fungi genera used in this regard, especially Penicillium simplicissimu ( $P$. simplicissimum) and Aspergillus terreus (A. terreus), Mulligan et al., 2000.

Locally, the experimental exploitation of U-bearing granitic rocks to produce uranium concentrates as well as production of the phosphoric acid from the phosphatic ores by the wet process yields huge amounts of TENORM. Such TENORM usually contains considerable amounts of the non-leached uranium (bout $15-20 \%$ of the original uranium content) in addition to about $80 \%$ of radium and other naturally occurring radionuclides (Bolivar, et al., 2000).

The objective of the present work is employing the biological treatment for the TENORM of the granitic tailing and the phosphogypsum by which the following benefits could be achieved:

-Reduction of the radioactivity concentrations of the TENORM (environmental and human health positive impact).

-Making the phosphogypsum by-product available for the civilian purposes (economical positive impact).

-Possibility to restore considerable amount of the lost uranium from the resulted waste (enhancing the uranium concentrate production).

\section{EXPERIMENTAL SETUP}

\section{TENORM Samples}

Tailing of the uranium mill experimental facility, the waste after uranium leaching process from the U-bearing granite in Gattar area (named as GW in this work), and the phosphogypsum by-product (PG) which resulted from manufacturing of phosphoric acid were the matters of this work. The uranium content in both the solid wastes was chemically deter- 
mined according to the method described by Davis and Gray (1964) where it is found as 251 and $12 \mathrm{mg} / \mathrm{kg}$ in the GW and $\mathrm{PG}$ radioactive solid wastes respectively.

It is worth to mention that, for some technical and cost circumstances, Ra-226 and some radionuclides will be considered in the ultimate application step and not incorporated during the preliminary steps of controlling factors studying.

\section{Organism}

Strain of $A$. terreus was isolated from both the concerned waste samples.

\section{Growth medium}

The fungal strain was propagated on the Dox liquid medium which composed of $\mathrm{NaNO}_{3}(2 \mathrm{~g} / \mathrm{l}), \mathrm{KH}_{2} \mathrm{PO}_{4}(1 \mathrm{~g} / \mathrm{l}), \mathrm{MgSO}_{4} \cdot 7 \mathrm{H}_{2} \mathrm{O}$ $(0.5 \mathrm{~g} / \mathrm{l}), \mathrm{FeSO}_{4} .5 \mathrm{H}_{2} \mathrm{O}(0.05 \mathrm{~g} / \mathrm{l})$ and sucrose $(30 \mathrm{~g} / \mathrm{l})$. The measured initial-pH of the growth medium was 6.5. The Dox medium was autoclaved at $1.5 \mathrm{~atm}$ for 20 minutes before the fungal propagation.

\section{Bioleaching Studies}

Generally, the uranium bioleaching process from the solid wastes was performed in $250 \mathrm{ml}$ Erlenmeyer flasks with $100 \mathrm{ml}$ of Dox medium. Four controlling factors were studied which were; incubation period, solid/ liquid ratio, incubation temperature and the initial $\mathrm{pH}$. After inoculation, the flasks were incubated at $28{ }^{\circ} \mathrm{C}$ (before getting the optimum temperature) with orbital shaking at 120 rpm for 3 days. Finally, the filtrate was centrifuged at $6000 \mathrm{rpm}$ to precipitate any more particles. It is worth to mention that for all the controlling factors and the ultimate application experiments, the Dox medium with the supplemented solid waste was autoclaved at $1.5 \mathrm{~atm}$ for 20 minutes before the spore inoculation to prevent any probable fungal activity except this by the inoculated spore after cooling the liquid Dox medium to the room temperature. Uranium content in the culture filtrate was determined by the same technique used for its determination in the solid wastes.

\section{Effect of incubation period}

The Dox media solution inoculated with the $A$. terreus was placed in $250 \mathrm{ml}$ Erlenmeyer flasks (100 ml per each flask) containing one gram of an individual solid waste. The flasks were incubated for different periods (1, 2, 3, 4 and 5 days) at $28{ }^{\circ} \mathrm{C}$ for 3 days in an orbital shaker at $120 \mathrm{rpm}$. Mycelial mats were harvested and the uranium content was determined after each incubation period.

\section{Effect of solid/liquid ratio}

One hundred $\mathrm{ml}$ of inoculated Dox liquid medium was placed in $250 \mathrm{ml}$ Erlenmeyer flasks. The flasks were supplemented with different concentrations from the GW and the PG wastes $(0.5,1,2,3$ and $4 \%(\mathrm{w} / \mathrm{v}))$. The flasks were incubated at $28{ }^{\circ} \mathrm{C}$ for 3 days in an orbital shaker at $120 \mathrm{rpm}$. After the incubation period, the mycelial mats were harvested and the uranium content was determined in the culture filtrate.

\section{Effect of incubation temperature}

Erlenmeyer flasks of $250 \mathrm{ml}$. containing mixtures of Dox liquid medium, one gram of the waste materials and the inoculated spore were incubated at different initial temperatures $\left(20,30,40\right.$ and $\left.50{ }^{\circ} \mathrm{C}\right)$ for 3 days with orbital shaking at $120 \mathrm{rpm}$ then the mycelial mats were harvested and the uranium content was determined in the culture filtrate.

\section{Effect of initial pH}

To study the $\mathrm{pH}$ effect on the uranium solubilization, the $A$. terreus was cultivated on the Dox media which was supplemented with $1 \%$ of the studied solid wastes and the initial $\mathrm{pH}$ was adjusted at different values $(1,2,3,4$ and 5) using $0.5 \mathrm{M} \mathrm{HCl}$ and $0.5 \mathrm{M} \mathrm{NaOH}$ and measured by the digital $\mathrm{pH}-$ meter model Inolab. The flasks containing the mixtures were incubated at $30{ }^{\circ} \mathrm{C}$ for 3 days with orbital shaking at $120 \mathrm{rpm}$. After harvesting the mycelial mats, the uranium content was determined in the culture filtrate. 
For the ultimate application, the achievable optimum conditions were worked collectively on the GW and PG waste samples. The uranium content in these samples was measured before and after the bioleaching. In addition, to verify the biological effect on other radionuclides, the radium-226 and some radionuclides were determined in the untreated and biologically treated samples using the Hyper Pure Germanium Detector which installed in the Nuclear Materials Authority laboratories.

\section{RESULTS, DISCUSSION AND CONCLUSION}

The uranium solubilization from both the U-bearing granitic tail and the phosphogypsum using the $A$. terreus gave variable responses to the variation in the controlling factors as shown hereafter;

-Increasing of the incubation period was accompanied by gradual increasing of uranium solubilization that reached its maximum value at 3 days of $A$. terreus growth where $57 \%$ and $45 \%$ of the original uranium content in the GW and the PG were solubilized respectively, beyond this period the U-solubilization showed markedly decreasing (Fig. 1). Insufficient oxygen transfer, limited nutrition provided to the microbes and/or attrition of the cells are the probable reasons that negatively affect the leaching process at the incubation periods above the optimum one (Mohapatra et al., 2007).

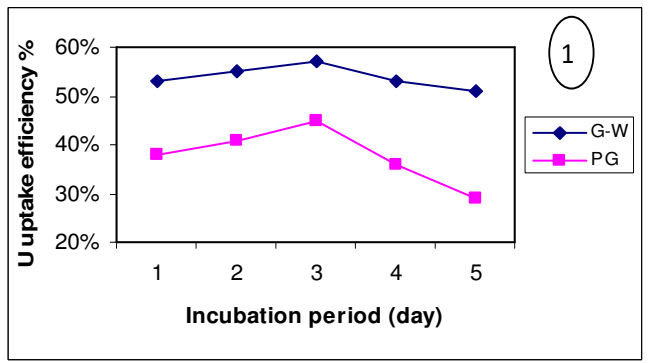

Fig.1 : Effect of the incubation period on the $U$ uptake by A.terreus from the GW and PG solid wastes
-Testing of the solid/liquid ratio effect revealed that the released amount of uranium by the A. terreus increased only from the solid/ liquid $0.5 \%$ to $1 \%$ then behaved decreasingly with increasing the solid/liquid ratio in the growth medium where the highest uranium solubilization from the wastes was obtained at $1 \%$ solid/liquid (Fig. 2). At this concentration, the $A$. terreus solubilized $65 \%$ and $45 \%$ of the uranium content in GW and the PG respectively. Such behavior could be ascribed to releasing of some toxic metals into the media at the high ore concentrations and consequently result in poisoning effect on the fungi that lead to decreasing their activity particularly production of the organic acids (Hughes \& Pool, 1991 and Gadd, 1993).

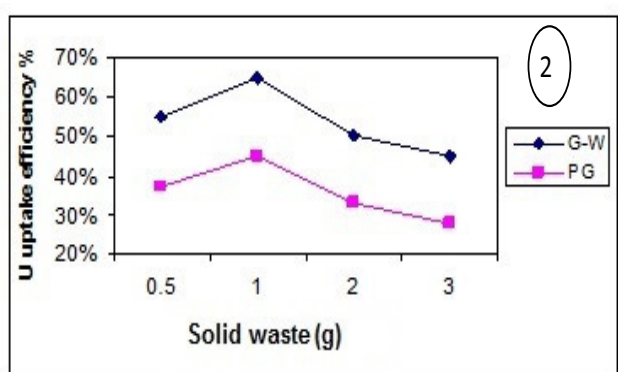

Fig.2 : Effect of the solid wastes concentration on the U uptake by A.terreus from the GW and PG solid wastes

-The maximum uranium solubilization was obtained at incubation temperature equals 30 ${ }^{\circ} \mathrm{C}$ where $65 \%$ of the uranium content in the GW was solubilized by the A. terreus while the solubilization efficiency reached to $42 \%$ in the PG waste (Fig. 3). Decreasing of uranium solubilization above this temperature is easily accepted particularly when we consider the damaging effect of the high temperature on the organism metabolic rate or even on its capability to be surviving (Mohapatra et al., 2008).

-Effect of the medium initial-pH variation on the uranium solubilization reflected a proportional relationship until the $\mathrm{pH}$ value reached up 4 while the higher value was accompanied by drastically decreasing of the 
solubilized uranium (Fig. 4). At pH 4, the efficiency of uranium solubilization was $71 \%$ and $62 \%$ from the GW and $\mathrm{PG}$ wastes respectively. As it behaved with the temperature variation, the $A$. terreus showed sensitive response to the $\mathrm{pH}$ variation. Decreasing of the fungus activity at $\mathrm{pH}$ values higher than 4 matches with the passive effect of the high $\mathrm{pH}$ on the organism metabolitic rate or even its threaten for the organism surviving (Mohapatra et al., 2008).

As mentioned before, for the ultimate application, the conducted optimum controlling factors (incubation period 3 dyas, solid/liquid ratio $1 \%$, incubation temperature $30^{\circ} \mathrm{C}$ and initial $\mathrm{pH} 4$ ) were employed together on sample from each waste. Uranium, radium and other radionuclides were matters for verification in the final application. While uranium was measured chemically, the other considered radioelements were measured radiometrically in the investigated wastes before and after the fungal activity to testify their behavior and response under the same conditions (Table 1).

The obtained results revealed that about $66.9 \%$ of the original uranium content in the GW waste was leached out into the culture filtrate by the fungal activity along with the optimum factors, while $62.5 \%$ of the original uranium content in the PG waste was leached out under the same conditions. On the other hand,

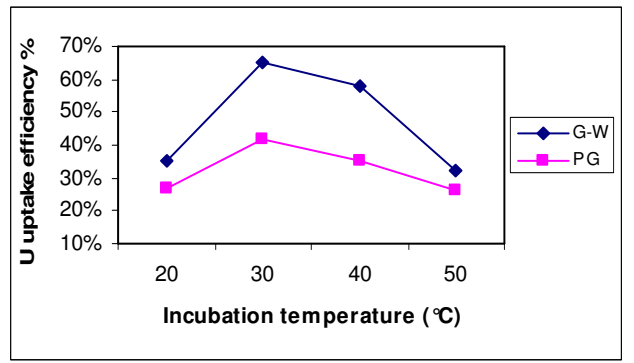

Fig. 3 : Effect of the incubation temperature on the U uptake by A.terreus from the GW and PG solid wastes

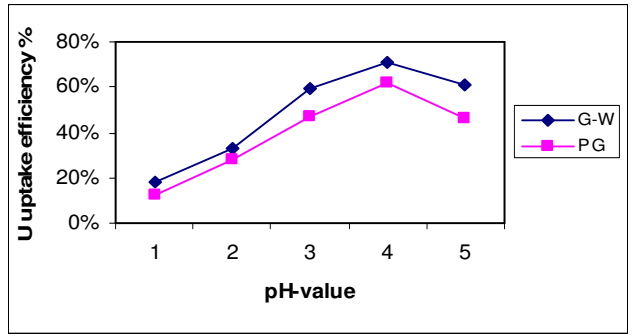

Fig.4 : Effect of the initial $\mathrm{pH}$ values on the $\mathrm{U}$ uptake by A.terreus from the GW and PG solid wastes

the radium similarly behaved as the uranium where $76.5 \%$ and $63 \%$ of the radium activity concentration was removed from the $\mathrm{GW}$ and PG wastes respectively by the $A$. terreus. The other radionuclides showed obvious variable reduction ratios after the biological treatment in both wastes (Table 1).

Table 1: Uranium content $(\mathrm{mg} / \mathrm{kg})$ and other radionuclides activity concentration $(\mathrm{Bq} / \mathrm{kg})$ in both solid wastes (GW \& PG) before and after the biological treatment

\begin{tabular}{|c|c|c|c|c|}
\hline & $\begin{array}{r}\text { GW } \\
\text { before } \\
\text { bio-treatment }\end{array}$ & $\begin{array}{r}\text { GW } \\
\text { after } \\
\text { bio-treatment }\end{array}$ & $\begin{array}{r}\text { PG before } \\
\text { bio-treatment }\end{array}$ & $\begin{array}{r}\text { PG after } \\
\text { bio-treatment }\end{array}$ \\
\hline $\mathrm{U}(\mathrm{mg} / \mathrm{kg})$ & 251 & 83 & 12 & $\overline{4.5}$ \\
\hline \multicolumn{5}{|c|}{ Activity concentration $(\mathrm{Bq} / \mathrm{kg})$} \\
\hline U-238 & $2273 \pm 64$ & $431 \pm 17$ & $385 \pm 15$ & $317 \pm 20$ \\
\hline Ra-226 & $11265 \pm 28$ & $2642 \pm 11$ & $488.74 \pm 5$ & $181.45 \pm 3$ \\
\hline Pb-214 & $10246 \pm 13$ & $2214 \pm 5$ & $644.75 \pm 2$ & $230.16 \pm 2$ \\
\hline Bi-214 & $10424 \pm 10$ & $2261 \pm 4$ & $582.16 \pm 2$ & $206.85 \pm 1$ \\
\hline U-235 & $130.77 \pm 1$ & $20.34 \pm 2$ & $29.19 \pm 2$ & $18.71 \pm 1$ \\
\hline Ac-228 & $221.03 \pm 4$ & $63.76 \pm 2$ & $54.57 \pm 1.6$ & $20.20 \pm 1$ \\
\hline Tl-208 & $223.74 \pm 3$ & $59.76 \pm 1$ & $34.00 \pm 0.9$ & $12.07 \pm 0.5$ \\
\hline
\end{tabular}


Referring to the original uranium content in both wastes and the leached-out uranium amount from each of them it was expected that all uranium content in the PG sample has to be leached by the A. terreus but realistically this is not the achieved situation where $37.5 \%$ of the original uranium content was left into the treated PG. This phenomenon could be ascribed to the uranium site, hence its daughters, in the GW (granitic sample) and PG (derivative of phosphate source) where in the GW uranium is mostly present as $\mathrm{U}^{6+}$ in secondary uranium minerals and/or labile uranium that are easily leached by the effect of the organic acids which excreted by the fungus. On the other hand, the uranium in the PG mainly incorporates into the crystal structure of the apatite mineral which could resist the effect of organic acids to some extent (Amin, 2012).

It is worth to mention that the retained radium activity concentration in the $\mathrm{PG}$ after the bio-treatment is less than the safe limits of activity concentration which established by the USEPA (1998) and meets $370 \mathrm{~Bq} / \mathrm{kg}$ for the PG to be released for civilian application although it is still higher than the permissible level which suggested later on as $150 \mathrm{~Bq} / \mathrm{kg}$ by the NRPI (2002).

In this regard, it has to point to that the used phosphogypsum sample was a matter of interest to reduce its radium activity concentration chemically (Mohammaden, 2011) where the treated phosphogypsum retaind only $44.5 \mathrm{~Bq} / \mathrm{kg}$ as Ra-activity concentration. Instantly, comparing the outputs of both the works, one can conclude that the chemical treatment is more effective relative to the biological one although both the techniques conducted the safe limit of Ra activity in the treated sample. However, other factors (e.g. the cost effect, the availability, the environmental issue, the particle size of the treated waste..etc.) shall be considered at preferring any of the two techniques.

Finally, the bio-technology was exhibited as an effective mean for TENORM treatment particularly with the phosphogypsum where the treated PG can be reused in several civilian purposes. However, to get the best outcome from any planned solid radioactive-waste management unit in the future, it is recommended to consider the integrity of both the chemical and the biological techniques.

\section{Acknowledgement}

Deep grateful and appreciation should be conveyed to Dr. Maisa M. Amin, the assistant professor of microbiology in NMA, for her effective and sincere help to fulfillment this work

\section{REFERENCES}

Amin, M. M.,2012. Factors controlling U-bioleaching from different Egyptian phosphate using P. simplissimum. J. of Environ. Sci., Mansoura Univ., 42(3) , 1665-180.

Bolivar, J. P.; Garcia-Tenorio, R., and Vaca, F., 2000. Radiological study of an estuarine system located in the south of Spain. Water Research, 34, 2941-2950.

Cabrera, G. J.; Gomez, M. and Cantero, D.,2005. Kinetic study of ferrous sulfate oxidation of Acidithiobacillus ferrooxidans in the presence of heavy metal ions. Enzyme and Microbial Technol., 36 (2,3), $301-306$.

Davis, S. W., and Gray, W.,1964. A rapid and specific titrimetric method for the precise determination of uranium using iron (II) sulphate as reductant. "Talanta" 11, 1203-1211.

Fang, D., and Zhou, L. X.,2007. Enhanced Cr bioleaching efficiency from tannery sludge with coinoculation of Acidithiobacillus thiooxidans T56 and Brettanomyces B65 in an air-lift reactor. Chemosphere, 69, $303-310$.

Fozia, A.; Haq, N. B.; Muhammead, A., and Muhammad, S.,2010. Leaching of metal ions from black shale by organic acids produced 
by A. niger. Appl. Clay Sci., 47, 356 - 361.

Gabriel, M., and Tomas, V.,2003. Bacterial oxidation of ferrous iron by Acidithiobacillus thiooxidans in the $\mathrm{pH}$ range $2.5-7.0$. Hydrometallurgy, 71(1-2), 149-158.

Gadd, G. M.,1993. Interaction of fungi with toxic metals. New Phytologist, 124, $25-60$.

Gu, X. Y., and Wong, J. W. C.,2007. Degradation of inhibitory substances by heterotrophic microorganisms during bioleaching of heavy metals from aerobically digested sewage sludge. Chemosphere, 69 (2), 311 - 318.

Hefnawy, M. A.; Hashad, A., and Maisa, A.,2002. Optimization of uranium leaching parameters by A. terreus and P. spinulosum. Proc. $3^{\text {rd }}$ Inter. Conf. of Fungi, 1, 17-34.

Hefnawy, M. A.; El-Said, M. H., and Maisa, M. A.,2003. Fungal leaching of uranium from its geological ores in Alloga area, west central Sinai, Egypt. Online J. Bio. Sci., 2, 346 -350 .

Hughes, M. N., and Pool, R. K.,1991. Metal speciation and microbial growth. The hard and soft facts. J. Genet. Microbial, 137, 725 -734 .

Hung-Yee, W., and Yen-Peng, T.,2006. Metal extraction from municipal solid waste (MSW) incinerator fly ash. Chemical leaching and fungal bioleaching. Enzyme and Microbial Technol., 38, 839-847.

Natural Radiation Protection Institute, NRPI.,2002. Radioactivity of building materials. http://www.suro.cz/en/prirodni/stavebni.html

Mishra, A.; Pradhan, N., , R. N.; Sukla, L. B., and Mishra, B. K.,2009. Microbial recovery of uranium using fungal strains. Hydrometallurgy, 92, $175-177$.

Mohammaden, T. F.,2011. Contribution to management of the phosphogypsum radioactive waste. Sedimentology of Egypt, 19, 165 173.
Mohapatra, S.; Bohidar, S.; Pradhan, N.; Kar, R. N., and Sukla, L. B.,2007. Microbial extraction of nickel from Sukinda chromite overburden by Acidithiobacillus ferrooxidans and Aspergillus strains. Hydrometallurgy, $85,1-7$.

Mohapatra, S.; Pradhan, N.; Mohanty, S., and Sukla, L. B.,2008. Recovery of nickel from lateritic nickel ore using $\mathrm{A}$. niger and optimization of parameters. Minerals Engineering, 5646-5649.

Mulligan, C. N.; Galvez, R., and Cloutier,2000. Bioleaching of copper mining residues by $\mathrm{A}$. niger. Water Sci. Technol., 41, 255 - 262.

Mulligan, C. N.; Kamali, M., and Gibbs, B. F.,2005. Bioleaching of heavy metals from a low grade mining ore using A. niger. J. Hazard Mater., 110, $77-84$.

Rutherford, P. M.; Dudas, M. J., and Samek, R. A.,1994. Environmental impacts of the phosphogypsum. Sci. Total Envir., 149, p. $1-38$.

Saravanan, P.; Pakshirajan, K., and Saha, P.,2007. Growth kinetics of an indigenous mixed microbial consortium during phenol degradation in a batch reactor. Bioresour. Technol., 99, $205-209$.

Sumera, S.; Haq, N. B., and Bahatti, T. M.,2002. Bioleaching studies of rock phosphate using A. niger, J. of Bio. Sci., 2 (2), 76-78.

Tong-Jiang, X., and Yen-Peng, T.,2009. Fungal bioleaching of incineration fly ash: Metal extraction and modeling growth kinetics. Enzyme and Microbial Technology, 44, 323328.

US Environmental Protection Agency,USEPA, 1998. Code of Federal Regulation. Title 40, Vol. 7, Parts 61.202 and 61.204 (40CFR61.202 and 40CFR61.204).

US Environmental Protection Agency, USEPA,2002. National Emission Standards for Hazardous Air Pollutants, Subpart R. 


\title{
النشاط الفطرى لخفض محتوى اليورانيوم و التركيزات الإشعاعيه لبعض النويدات المشعه فى المواد المشعه طبيعيا و التى تعرضت لتكنولوجيات الإنعاعيا التصنيع التصني
}

\author{
طارق فهمى محمدين
}

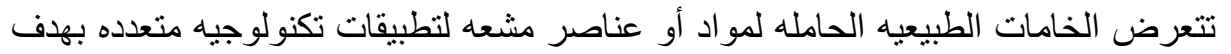

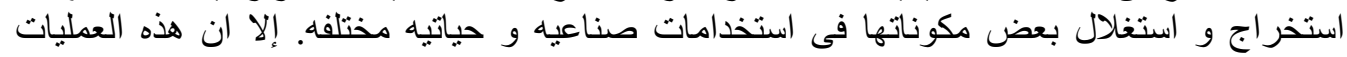

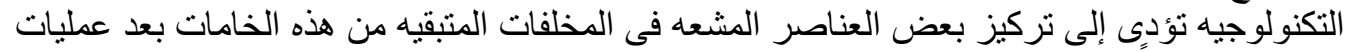

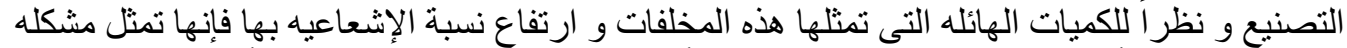

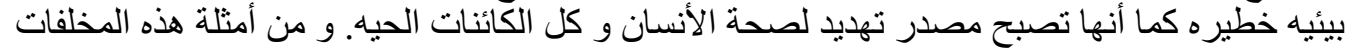

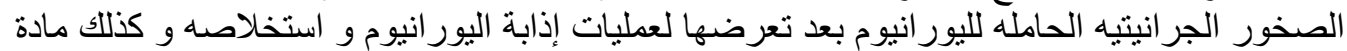

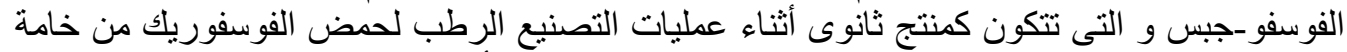

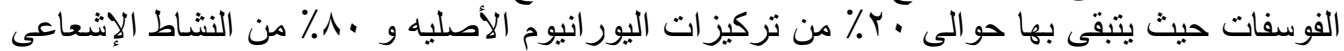

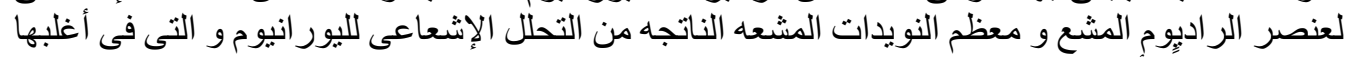
تكون مصدر الأشعة جاما.

قد تعرض هذا البحث لمعالجة المخلف الناتج من الصخور الجرانيتيه الحامله لليور انيوم بعد الإندا

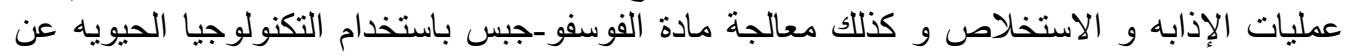

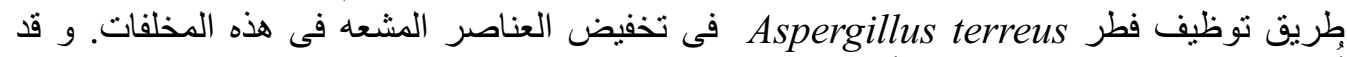

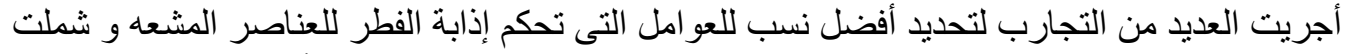

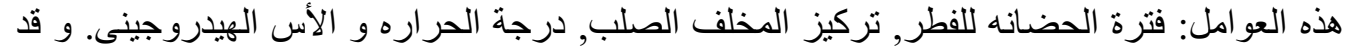

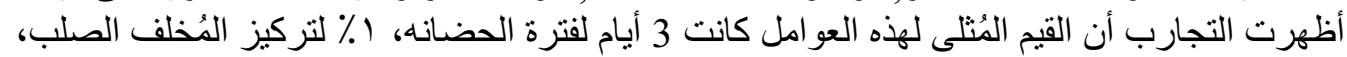

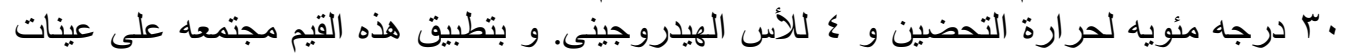

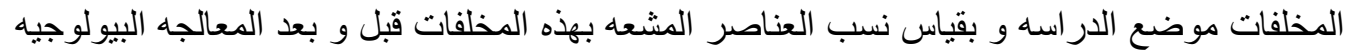

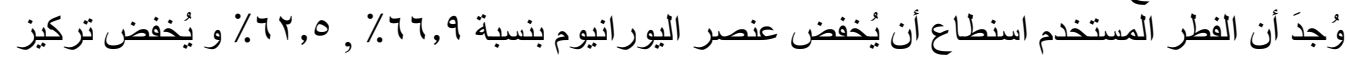

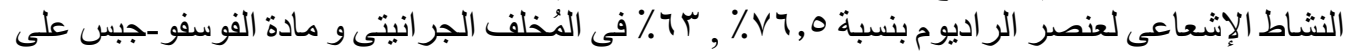

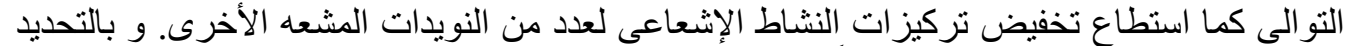

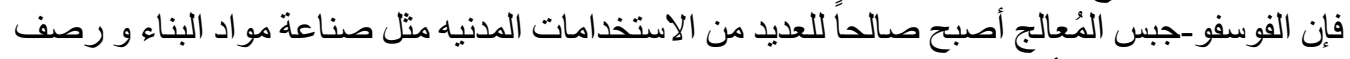

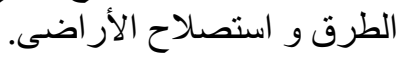

